reasonable ground against the constant varying of prescriptions when there is no occasion for it. The hostility of the apothecaries to him, according to his own account, arose from his being "always inviolably attached to the Interest and Welfare of my Patient and entirely regardless of these Gentlemen's unwarrantable Gains." These attacks did not pass unnoticed, and in $1733 \mathrm{H}$. Bradley, surgeon, criticises the "Ancient Physician's Legacy," and makes some " anim adversions on his scurrilous Treatment of the Professors of Physic in general, with a word or two on the uselessness of his Legacy to all Private Families." Daniel Turner, "of the College of Physicians," who in the same year "imparGially surveys the "Ancient Physician's Legacy," refers to the Guaiaquil incident in the following terms: "I think the Doctor had much better have left out his bravado of having taken two cities by storm, unless he thinks it an honour to a physician to kill and slay, and after so plunder the innocent, those who never wronged him, and to carry off the spoil ; a good prelude, this, to the bloodshed after among his own men." (Dover had had them bled copiously (or the plague.) 'Turner hints that Dr. D-—v's quicksilver did not a little to hasten the end of the celebrated tragedian, Barton Booth, to whom he had given between May 3rd and 3th within two ounces of two pounds of mercury.

Like his master, Dover's only affiliation with the Royal College of Physicians was through the minimum qualification of the Licence. Sydenham and Morton, the two most distinguished English clinical physicians of the seventeenth century, were regarded as innovators and "sectaries" by the heads of the College, who, as Sydenham remarks, took fire at his attempts to reduce practice to greater easiness and plainmess. The coolness and moderation of the master were not imitured by the "Ancient Physician," who in the sixth edition attacks the gentlemen of the faculty, and warns unwary people "not to take every graduate for a physician nor a clan of prejudiced gentlemen for oracles." He added to his legacy the "Statuta Moralia," or, as he terms it on the title-page, "the moral conrersation of the College of Physic in Latin and Inglish, by "way of appendix, cogether with a Digression." Dover affirms boldly that the whole purport of the "Conversation" is to conceal their ignorance and to deceive their miserable patients, but he avers his desire is "more to do justice to mankind than to irritate and provoke a Set of Gentlemen who, like moles, work underground lest their practices shonld be discovered to the Populace." He again refers to the relations of the apothecarles with the physicians in the following terms: "The Apothecaries, generally speaking, have it in their Power to recommend the Physician, which is the wrongest Step the Patient can possibly take: 'The Physician, to gratify the Apothecary, thinks himself obliged to order ten times more Physic than the Patient really wants, by which means he often ruins his Constitution, and too of ten his Life ; otherwise how is it possible an Apothecary's Bill in a Fever should amount to Forty or Fifty or more Pounds? Nay, I have been credibly inform'd, that several of those Apothecaries have declared they never would call in a Physician, but what should put Fifteen or 'I'wenty Shillings a Day into their Pockets: What must the Conscience of such Physicians be, that would forfeit their Reputation, and everything that is dear to them, by cheating for others? I would venture to say, Neither Sydenham's nor Radcliffe's Bills did ever amount to Forty Shillings in a Fever, and yet they recover'd their Patients without the Rule, at present prescribed, of Vomiting, Bleeding, and multiplying Blisters in all Cases whatsoever; so since this is to be their Rule of Practice, they are very indifierent in their Enquiries what the Patient's Disease is."

Dover continued to practise in London, and in the seventh edition of the "Ancient Physician's Legacy" there is a letter to him from Catherine Hood, dated Nov. 6th, 1738, in which she speaks of having consulted him in 1737. In 1742 appeared the sixth edition of the Legacy, which must have been issued by the author, as he speaks on the title page of fifty-eight years of practice. $\mathrm{He}$ is stated by Munk to have died in 1741 or 1742 , probably the latter, but his name does not appear in the register of deaths in the Gentleman's Magavine in either of those years. Doubtless the old buccaneer, described "as a man of rough temper, who could not easily agree with those about him," was a striking figure as he passed along the Strand to the Jerusalem Coffee-house, where he saw his patients. A good fighter, a good hater, as, alas, so many physicians have been, his weaknesses and evil behaviour we may forget, but Captain Thomas Dover, who on Feb. 2nd, 1709, found "Robinson Crusoe," the world should riot forget; and we also of his craft have cause daily to remember with gratitude the student and friend of the great Sydenham, who had the wit, in devising a powder, to remember his master's injunction: "Sine papaveribus, sine opiatis, et medicamentis ex iis confectis, manca et clauda esset medicina."

\section{CASE"OF A LARGE CYSTIC BRONCHOCELE NECESSITATING COMPLETE REMOVAL OF THE THYROID GLAND.}

BY SIR WILLIAM STOKES, F.R.C.S. IRET.,

SURGEON IN ORDINARY TO HER MAJESTY TRE QUEEN IN IRLLAND; PHOFESSOR OF SURCY,RY, ROYAI COLLEGE OF SURGEONS Li IRKA AND, \&C.

Trit following case, in which I removed an exceptionally large cystic bronchocele, is, as all such cases are, replete with surgical interest. For many of the notes of the case I am indebted to Mr. W. Taylor, late house surgeon to the Meath Hospital.

A woman aged thirty-three, single, suffering from a large tumour of the neck, was adrnitted into the Meath Hospital under my care on March 13th, 1895, having been recommended to me by Mr. J. H. Fergusson of Killigordon, co. Donegal. The patient stated that the tumour had existed

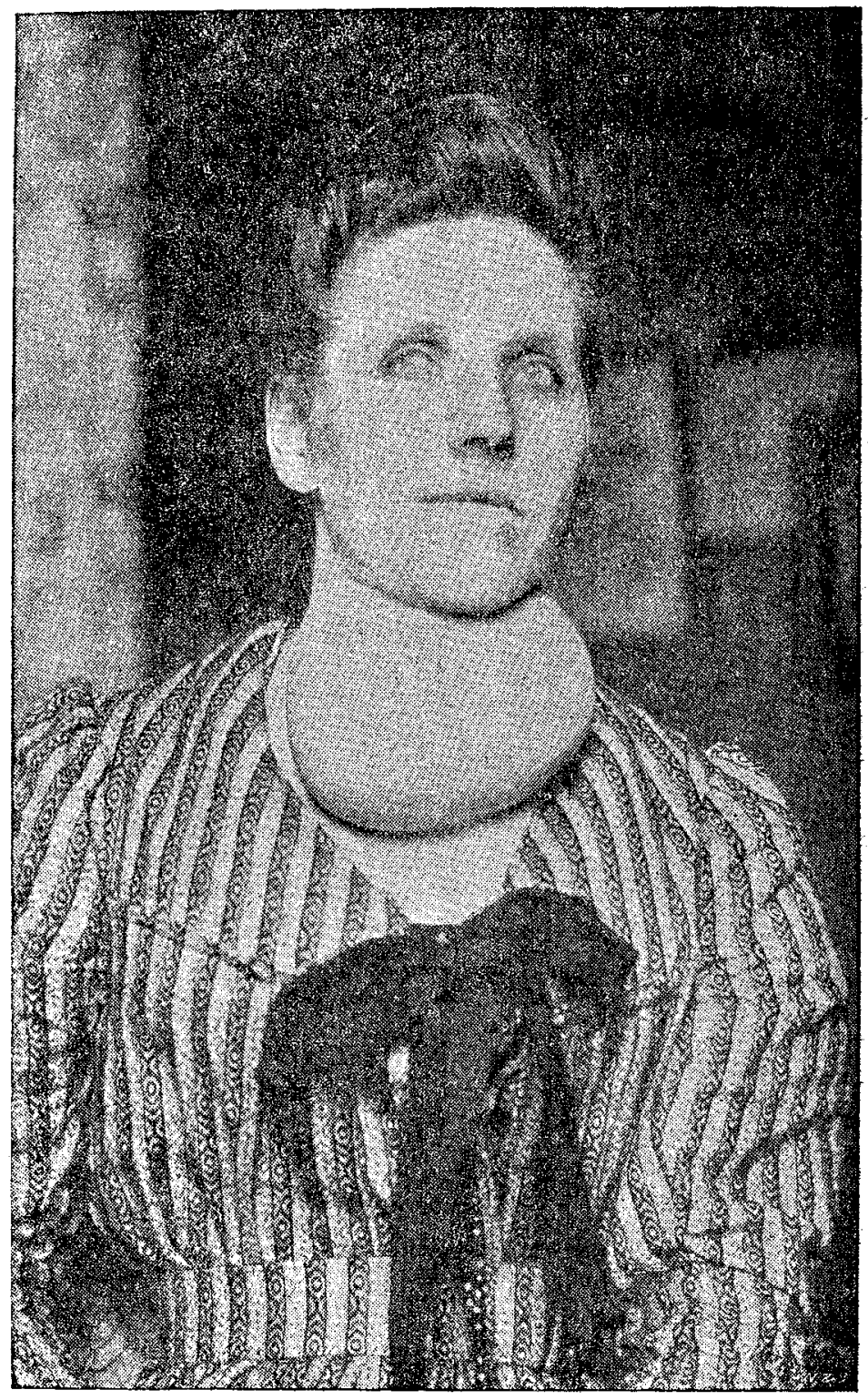

as long as she could remember, but that latterly it had greatly increased in size. On two occasions it had been tapped by Mr. Fergusson, which operations were attended with a sensible, though only temporary, diminution in its size. On her admission the tumour was found to be very tense but fluctuating, extending from the chin to the sternum in the middle line and outwards to points well 
behind the posterior margins of both sterno-mastoids. The chin rested on a sulcus on the upper margin of the tumour. Below, it appeared to pass downwards behind the sternum, which at the time of the operation I found it had done. The patient experienced latterly some difficulty in swallowing, especially solids, which she said always seemed to "stick" when they came opposite to the centre of the tumour. The diagnosis I made was that of cystic bronchocele, and I had no hesitation in recommending its excision. On March 20th, assisted by Sir P. C. Smyly, Mr. Hepburn, and Mr. Taylor, I removed the tumour. The patient having been anæsthetised by chloroform, I made in the middle line a vertical incision over it about three inches in length, and from the centre of this two incisions were made obliquely upwards and outwards, about one inch and a half in length. The skin flaps were then dissected off the tumour, which I then proceeded to enucleate. This was" not attended with the diffculties I had anticipated, and which I had experienced in former excisions of the thyroid gland. The hæmor-

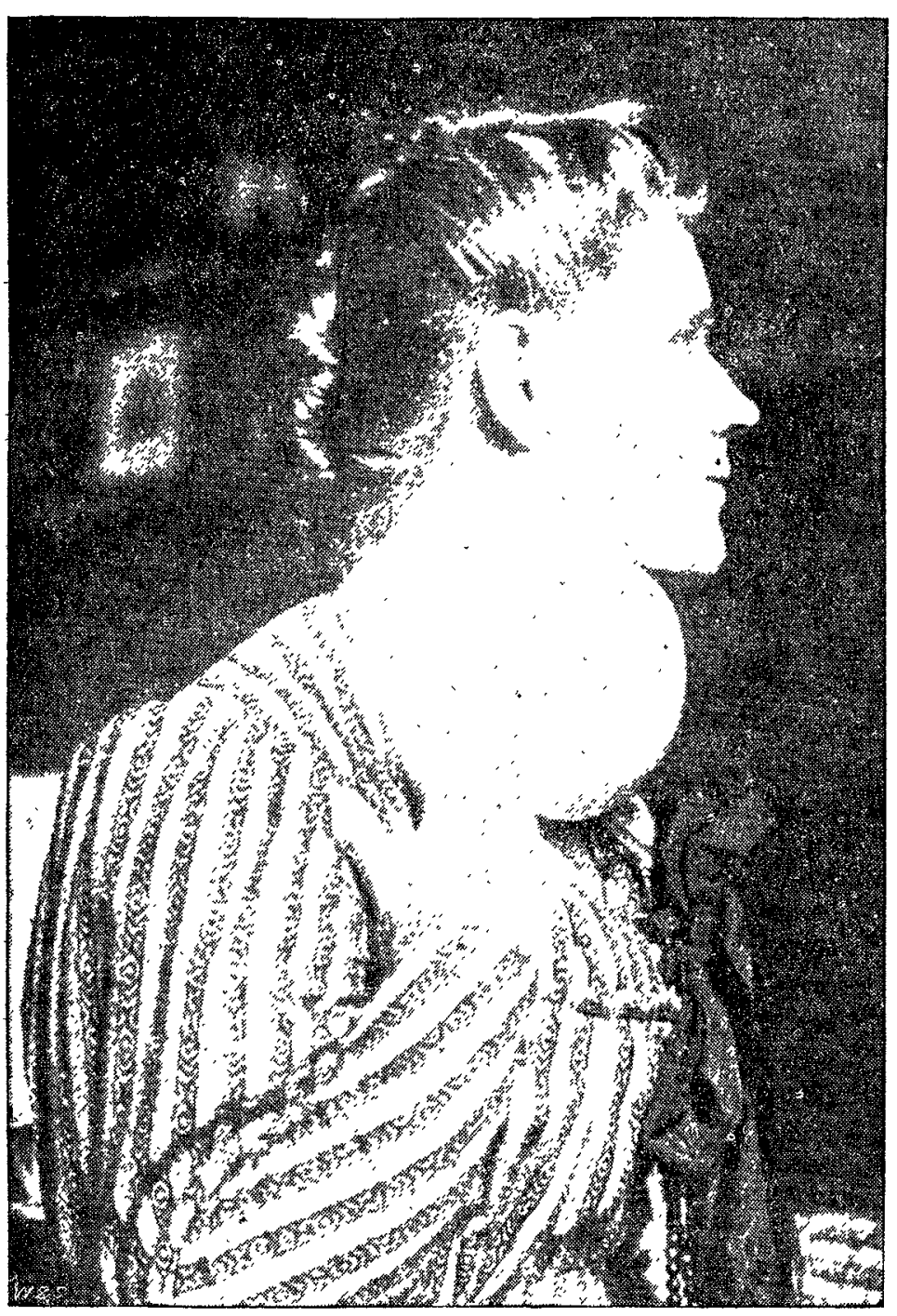

rhage was comparatively slight, and few vessels had to le ligatured until I reached the posterior aspect of the growth, at which situation many large vessels supplying it entered. These were carefully secured by double ligatures and the vessels divided between them. The only moment of much anxiety I had was when I was lifting up the portion of the tumour which had passed behind the sternum, as I feared it might have formed attachments to the sheaths of some of the great vessels at the root of the neck. Happily, these apprehensions were found to be groundless, and the tumour was removed without any untoward accident, leaving the trachea quite bare, and a large cavity behind the upper part of the sternum in which the transverse portion of the arch of the aorta and the great vessels of the neck with the left innominate rein could easily be seen. The wound was then thoroughly irrigated with a warm boric solution, and after being well dusted over with boracic acid its edges were brought together with very fine, carefully asepticised silk sutures, and a perforated glass drainage tube was inserted at the lower angle of the wound. After the operation the patient passed a quiet day and night, the only element of disturbance keing a certain : mount of nausea and occasional vomiting, due doubtless to the anæsthetic. On the following day, owing to there being evidence of considerable serous discharge, the wound was dressed. Its appearance was quite satisfactory, and the drainage tube was removed. During the convalescence of the patient the chief source of anxiety I had was owing to the development of an attack of broncho-pneumonia accompanied by considerable febrile disturbance; but on March 30th these symptoms subsided, the temperature (which had risen as high as $104^{\circ} \mathrm{F}$.) was normal, and the wound had healed. From this time the patient's progress to recovery was uninterrupted, and she soon afterwards left for home in perfect health. As the removal of the thyroid gland was apparently a complete one I recommended the patient to take thyroid extract in small quantities daily, a suggestion which I hope is still being carried out. The last tidings received of the patient were all that could be desired.

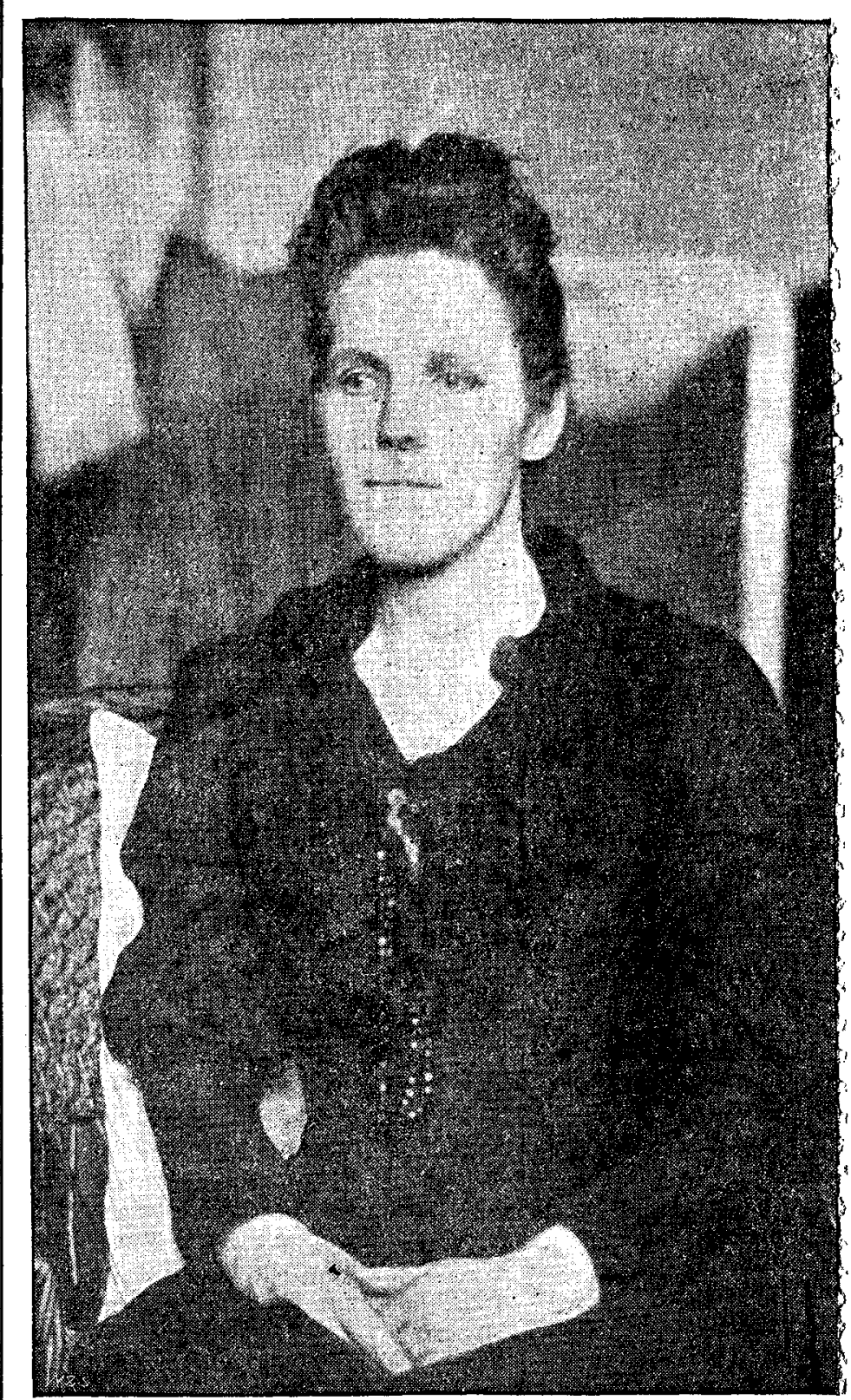

The accompanying illustrations, taken from photographs, give faithful representations of the patient before and after the operation.

Dublin.

BRITISH GyN RCOLOGICAL SOCIETY.-At the annual meeting, to be held on Thursday, Jan. 9th, 1896, the following resolutions of council (dated Feb. 28th and April 4th, 1895, respectively) will be submitted to the Fellows, with a view to their being added to the by-laws of the society: -1 . That it is undesirable that any member of the medical profession practising homœopathy should be proposed as a Fellow of the society. 2. That it is contrary to the ethics of the British Gynxcological Socicty that any of its Fellows should advertise their publications or otherwise bring themselves before the notice of the public by advertising in any way through the medium of the lay papers. That circulars of the nature of an advertisement sent ever to members of the medical profession generally would be regarded with disapprol ation by the council. 